\title{
Divergência genética entre acessos açucarados e não açucarados de mandioca
}

\author{
Eduardo Alano Vieira(1), Josefino de Freitas Fialho(1), Fábio Gelape Faleiro(1), Graciele Bellon ${ }^{(1)}$, \\ Kenia Graciele da Fonseca(1), Luiz Joaquim Castelo Branco Carvalho(2), Marilia Santos Silva(1), \\ Silvana Vieira de Paula-Moraes ${ }^{(1)}$, Mário Ozeas Sampaio dos Santos Filho(1) \\ e Karina Nascimento da Silva(1)
}

\begin{abstract}
(1)Embrapa Cerrados, BR 020, Km 18, CEP 73310-970 Planaltina, DF. E-mail: vieiraea@cpac.embrapa.br, josefino@cpac.embrapa.br, ffaleiro@cpac.embrapa.br, bellon@cpac.embrapa.br, kenia@cpac.embrapa.br, marilia@cpac.embrapa.br, silvana@cpac.embrapa.br, mario.sampaio@cpac.embrapa.br, karina.nascimento@cpac.embrapa.br ${ }^{(2)}$ Embrapa Recursos Genéticos, Parque Estação Biológica, Avenida W5 Norte, CEP 70770-900 Brasília, DF. E-mail: carvalho@cenargen.embrapa.br
\end{abstract}

Resumo - O objetivo deste trabalho foi estimar a divergência genética entre acessos de mandioca açucarados e não açucarados, por meio de marcadores moleculares, caracteres quantitativos e qualitativos, bem como determinar a correlação entre essas estimativas. Foram utilizados quatro acessos de mandioca açucarados e quatro não açucarados, com duas variedades locais e duas comerciais. Os acessos foram avaliados em campo, em laboratório, com marcadores RAPD, quanto a 12 caracteres quantitativos e 33 morfológicos. Foram estimadas as matrizes de dissimilaridade/distância genética entre os acessos, por meio dos caracteres qualitativos e quantitativos e da significância da correlação entre as matrizes. A divergência genética entre os acessos foi elevada e os acessos açucarados foram diferenciados das variedades não açucaradas locais e comerciais. As distâncias estimadas, por meio de marcadores moleculares e caracteres qualitativos, evidenciaram elevada associação entre si e associação moderada com a estimada por meio de caracteres quantitativos.

Termos para indexação: Manihot esculenta, melhoramento genético, recursos genéticos, variabilidade genética.

\section{Genetic divergence among sugary and nonsugary cassava accessions}

Abstract - The objective of this work was to estimate the genetic divergence among sugary and nonsugary cassava accessions, through molecular markers, and quantitative and qualitative characters, as well as to determine the correlation among these estimates. Four sugary cassava accessions and four nonsugary ones were used, including two landraces and two nonsugary improved varieties. The accessions were evaluated in field conditions and in laboratories, with RAPD markers, in 12 quantitative and 33 qualitative characters. Matrixes of genetic dissimilarity/distance among accessions were estimated, based on qualitative and quantitative characters, molecular markers, and on the correlation significance among matrixes. High genetic divergence among the evaluated accessions was observed, the sugary accessions were differentiated from the landraces and improved nonsugary varieties. The distances estimated through molecular markers and qualitative characters showed the high association among each other and moderate association with the distance estimated through quantitative characters.

Index terms: Manihot esculenta, genetic breeding, genetic resources, genetic variability.

\section{Introdução}

No Brasil, centro de origem e diversidade da mandioca (Manihot esculenta Crantz) (Olsen, 2004), a espécie apresenta elevada variabilidade genética e é cultivada em todas as regiões, para os mais diversos fins (Carvalho \& Schaal, 2001; Ferreira et al., 2008). Parte dessa variabilidade vem sendo conservada em bancos de germoplasma, como o Banco Regional de Germoplasma de Mandioca do Cerrado (BGMC), que reúne cerca de 500 acessos da espécie $M$. esculenta Crantz, e constitui-se em importante fonte de genes para programas de melhoramento genético (Vieira et al., 2007b).

Recentemente, foram introduzidos no BGMC acessos que apresentam fenótipos bioquímicos diferenciados (açucares livres nas raízes tuberosas), popularmente conhecidos como mandiocas açucaradas ou mandiocabas, e que evidenciam o seguinte potencial de produção na indústria: xarope de glicose, sem a necessidade da hidrólise do amido; amido com

Pesq. agropec. bras., Brasília, v.43, n.12, p.1707-1715, dez. 2008 
variabilidade na proporção amilose/amilopectina; amidos do tipo glicogênio ou do tipo ceroso; bebidas fermentadas; álcool para a indústria de cosméticos; amidos específicos para a indústria siderúrgica; e álcool combustível, entre outras utilidades (Carvalho et al., 2000, 2004). Entretanto, esses acessos ainda não foram suficientemente estudados quanto à divergência genotípica e fenotípica, o que é fundamental para sua conservação e utilização no melhoramento genético.

Entre as ferramentas utilizadas, na estimativa da divergência genética em um conjunto de genótipos, destacam-se a utilização de marcadores moleculares e a de caracteres fenotípicos qualitativos ou quantitativos (Vieira et al., 2007a). Marcadores moleculares vêm sendo utilizados com elevada freqüência na estimativa da divergência genética entre acessos de mandioca (Carvalho \& Schaal 2001; Asante \& Offei, 2003; Zacarias et al., 2004; Ferreira et al., 2008), pois constituem excelente ferramenta para a obtenção de informações contidas no genoma de um indivíduo. Entre as diversas técnicas de marcadores moleculares, o RAPD (polimorfismo de DNA amplificado ao acaso) merece destaque, pelo baixo custo, pela rápida e fácil execução e pelo fato de não exigir um conhecimento prévio do genoma. Em relação aos caracteres fenotípicos, os marcadores moleculares apresentam a vantagem de não sofrer influência do ambiente, porém a desvantagem de acessar o genoma como um todo e não somente as regiões responsáveis pela manifestação dos caracteres de interesse.

Caracteres fenotípicos qualitativos e quantitativos, em associação com as técnicas de análise multivariada, também vêm sendo empregados na quantificação da divergência genética em mandioca (Mkumbira et al., 2003; Nick et al., 2008). Entre os caracteres fenotípicos que podem ser utilizados, os mais influenciados pelo ambiente são os quantitativos. Entretanto, esses caracteres são muito importantes na avaliação de acessos, uma vez que refletem o real potencial produtivo dos acessos e a possibilidade de sua utilização de forma direta ou no melhoramento genético. Os caracteres qualitativos têm a sua importância na caracterização de germoplasma, por sua relativamente fácil aferição, seu menor custo e por serem menos influenciados pelo ambiente do que os caracteres quantitativos.

Apesar da importância dos estudos de divergência genética, não se conheciam relatos na literatura destes estudos sobre acessos de mandioca açucarados e não açucarados por meio da utilização de marcadores moleculares e caracteres morfoagronômicos, de forma conjunta e complementar, a fim de orientar os programas de melhoramento genético.

O objetivo deste trabalho foi estimar a divergência genética entre acessos de mandioca açucarados e não açucarados, por meio de marcadores moleculares, caracteres quantitativos e qualitativos, bem como determinar a correlação entre essas estimativas.

\section{Material e Métodos}

No presente estudo, foram avaliados oito acessos de mandioca, mantidos no Banco Regional de Germoplasma de Mandioca do Cerrado (BGMC) (Tabela 1). Os acessos foram avaliados em campo, entre 3 de outubro de 2006 e 3 de outubro de 2007, em área experimental da Embrapa Cerrados, Planaltina, DF, $15^{\circ} 35^{\prime} 30^{\prime \prime} \mathrm{S}, 47^{\circ} 42^{\prime} 30^{\prime \prime} \mathrm{W}$ e altitude de $1.000 \mathrm{~m}$. O clima da região é do tipo Aw, segundo a classificação de Köppen. O delineamento experimental foi o de blocos ao acaso, com três repetições, em que cada parcela consistiu de quatro linhas de dez plantas, em espaçamento de $1,20 \mathrm{~m}$ entre linhas e $0,80 \mathrm{~m}$ entre plantas, e área útil de $16,36 \mathrm{~m}^{2}$, constituída pelas 16 plantas centrais de cada parcela. A seleção do material de propagação e os tratos culturais foram feitos conforme as recomendações do sistema de produção de mandioca para a região do Cerrado (Souza \& Fialho, 2003).

Foram avaliados os seguintes caracteres quantitativos: altura da planta (AP); altura da primeira ramificação(APR); peso da parte aérea sem a cepa (PPA); peso da cepa (PC); produtividade de raízes (PR); percentagem de amido nas raízes (AM), por meio do método da balança hidrostática, descrito por Grosmann \& Freitas (1950); comprimento do lóbulo da

Tabela 1. Acessos de mandioca açucarados e não açucarados, seus respectivos nomes comuns e locais de coleta/procedência.

\begin{tabular}{|c|c|c|c|}
\hline Acessos & $\begin{array}{l}\text { Nome } \\
\text { comum }\end{array}$ & $\begin{array}{c}\text { Local de } \\
\text { coleta/procedência }\end{array}$ & Tipo \\
\hline BGMC 1208 & Sem denominação & Bom Jesus do Tocantins, PA & Não açucarado \\
\hline BGMC 1210 & Sem denominação & Igarapé -Açu, PA & Não açucarado \\
\hline BGMC 1212 & Sem denominação & Maracanã, PA & Açucarado \\
\hline BGMC 1213 & Sem denominação & Tracuateua, PA & Açucarado \\
\hline BGMC 1211 & Sem denominação & Igarapé-Açu, PA & Açucarado \\
\hline BGMC 1217 & Iguaçu & Igarapé-Açu, PA & Açucarado \\
\hline BGMC 753 & IAC 756-70 & IAC - Campinas, $\mathrm{SP}^{(1)}$ & Não açucarado \\
\hline BGMC 436 & IAC 12 & IAC - Campinas, $\mathrm{SP}^{(1)}$ & Não açucarado \\
\hline
\end{tabular}


folha (CLF), obtido pela aferição de uma folha do terço médio de cada planta da área útil da parcela, seis meses após o plantio; largura do lóbulo da folha (LLF), obtida pela aferição de uma folha do terço médio de cada planta da área útil da parcela, seis meses após o plantio; comprimento do pecíolo (CP), obtido pela aferição de uma folha do terço médio de cada planta da área útil da parcela, seis meses após o plantio; número médio de ninfas e adultos de percevejo-de-renda (NMP), obtido pela contagem do número de ninfas e de adultos, em três avaliações (28/12/06, 9/1/2007 e 26/2/2007), em três plantas por parcela; incidência de bacteriose (IB) em percentagem, obtida pela contagem do número total de plantas com sintomas da moléstia, nas parcelas, em duas avaliações (13/3/2007 e 18/5/2007); e severidade da bacteriose (SB), por meio da avaliação de três plantas por parcela, em duas avaliações (13/3/2007 e $18 / 5 / 2007$ ), pela escala de notas descrita por Ramos \& Takatsu (1987), que varia de 1 a 5, em que: 1 significa que não há sintomas visíveis; 2 , que há apenas manchas foliares; 3 , que há manchas foliares e secreção no caule; 4, que há manchas foliares, secreção no caule e desfolha; 5 , que há morte descendente.

Os dados obtidos foram submetidos à análise de variância, e as médias foram comparadas por meio do teste de Scott \& Knott (1974), a 5\% de probabilidade, por meio do programa computacional Genes (Cruz, 2001). Os dados de SB foram transformados para $\mathrm{x}^{0,5}$, antes da análise de variância.

No momento da colheita, também foi determinado o teor de ácido cianídrico ( $\mathrm{HCN})$ nas raízes tuberosas, por meio do método qualitativo descrito por Willians \& Edwards (1980), a partir de cinco raízes tuberosas tomadas ao acaso por parcela. Como os dados de HCN obtidos foram qualitativos, eles não foram utilizados nas análises estatísticas. Posteriormente foi estimada a distância generalizada de Mahalanobis $\left(D^{2}\right)$ (Mahalanobis, 1936), entre os oito acessos de mandioca, com base nos 12 caracteres quantitativos aferidos, por meio do programa computacional GENES (Cruz, 2001).

Os 33 caracteres qualitativos aferidos conforme Fukuda \& Guevara (1998), foram: cor da folha apical; pubescência do broto apical; forma do lóbulo central; cor do pecíolo; cor do córtex do caule; cor externa do caule; comprimento da filotaxia; presença de pedúnculo nas raízes; cor externa da raiz; cor do córtex da raiz; cor da polpa da raiz; textura da epiderme da raiz; presença de floração; cor da folha desenvolvida; número de lóbulos; cor da epiderme do caule; hábito de crescimento do caule; cor dos ramos terminais nas plantas adultas; constrições da raiz; cor da nervura; posição do pecíolo; proeminência das cicatrizes foliares; comprimento das estípulas; margem das estípulas; hábito de ramificação; sinuosidade do lóbulo foliar; forma da raiz; tipo de planta; comprimento médio da raiz; diâmetro médio da raiz; destaque da película da raiz; destaque do córtex da raiz; e posição das raízes. A dissimilaridade genética entre os oito acessos, com base nos 22 caracteres qualitativos que evidenciaram variabilidade entre os acessos, foi estimada por meio do complemento do índice de coincidência simples, com auxílio do programa computacional GENES (Cruz, 2001).

O DNA utilizado nas análises com marcadores RAPD foi extraído a partir de folhas em estágio intermediário de maturação, por meio do método do CTAB (2,8\%), com modificações propostas por Faleiro et al. (2003), e quantificado com base na absorbância a $260 \mathrm{~nm}$; e a análise de pureza foi feita com base na relação de absorbância a 260 e $280 \mathrm{~nm}$.

Posteriormente, as amostras de DNA de cada acesso foram amplificadas para a obtenção de marcadores RAPD, conforme Costa et al. (2005). $\mathrm{Na}$ obtenção dos marcadores, foram utilizados 12 iniciadores decâmeros (Operon Technologies Inc., Alameda, CA, EUA: OPD) $(02,08,18)$, OPF (08), OPG $(05,08,09,15$ e 16), OPH $(10,16$ e 17). Os fragmentos amplificados foram separados eletroforeticamente por quatro horas, a 90 volts, em gel de agarose $(1,2 \%)$ corado com brometo de etídio, submerso em tampão TBE (Tris-Borato $90 \mathrm{mM}$, EDTA $1 \mathrm{mM}$ ). Ao término da corrida, os géis foram fotografados sob luz ultravioleta. Os produtos das reações de amplificação (marcadores RAPD) foram classificados pela presença (1) ou ausência (0) de bandas e, posteriormente, foram convertidos em matriz de dados binários, a partir da qual foi estimada a dissimilaridade genética entre os acessos, com base no complemento do coeficiente de similaridade de Jaccard (Jaccard, 1908).

Com base nas matrizes de distância/dissimilaridade genética, obtidas a partir da análise com caracteres quantitativos, qualitativos e marcadores RAPD, foram confeccionados três dendrogramas, por meio do método de agrupamento da distância média(UPGMA). 
$\mathrm{O}$ ajuste entre as matrizes de distância/dissimilaridade e os respectivos dendrogramas foi estimado pelo coeficiente de correlação cofenética (r) (Sokal \& Rohlf, 1962), por meio do programa computacional NTSYS pc 2.1 (Rohlf, 2000). A estabilidade dos agrupamentos foi computada por meio da análise de "bootstraping", com 500 replicações por meio do programa GENES (Cruz, 2001), com exceção da matriz de dissimilaridade, obtida por meio dos caracteres qualitativos, uma vez que os programas disponíveis não oferecem essa função.

Para a estimativa da significância da correlação (associação) entre as matrizes de distâncias obtidas, foi empregado o teste de comparação de matrizes de Mantel, com 1.000 permutações (Mantel, 1967), por meio do programa NTSYS pc 2.1 (Rohlf, 2000).

\section{Resultados e Discussão}

A análise de variância mostrou variação significativa $(p<0,05)$ entre os acessos, para todos os caracteres quantitativos aferidos, o que revela a existência de diferenças no potencial agronômico desses acessos (Tabela 2). A presença de ampla variabilidade era esperada, uma vez que foram avaliadas constituições genéticas de diferentes origens e níveis de melhoramento (Tabela 1), como já havia sido relatado sobre a mandioca por Borges et al. (2002) e Nick et al. (2008). Os coeficientes de variação foram de 4,23\% para o caráter AM a 24,87\% para o caráter IB.

O acesso açucarado mais produtivo, no ano agrícola de 2006/2007, foi o BGMC 1213, uma vez que, aos 12 meses de idade sua PR foi de $8.900 \mathrm{~kg} \mathrm{ha}^{-1}$, enquanto o acesso BGMC 753, recomendado para o cultivo na região do Cerrado brasileiro, mostrou PR de $28.183 \mathrm{~kg} \mathrm{ha}^{-1}$ (Tabela 2). A baixa PR dos acessos açucarados, aliada à grande suscetibilidade à bacteriose (Xanthomonas axonopodis pv. manihotis), conforme as médias elevadas apresentadas para IB e $\mathrm{SB}$, inviabilizam o cultivo desses acessos na região do Cerrado brasileiro (Tabela 2). É evidente a necessidade de melhoramento genético, para a transferência desses genes de fenótipo açucarado nas raízes tuberosas, para cultivares de mandioca adaptadas às condições do Cerrado brasileiro, mais produtivas e resistentes à bacteriose; dessa forma, o sistema de produção de mandiocas açucaradas pode ser viabilizado nesta região. Uma característica de interesse, manifestada

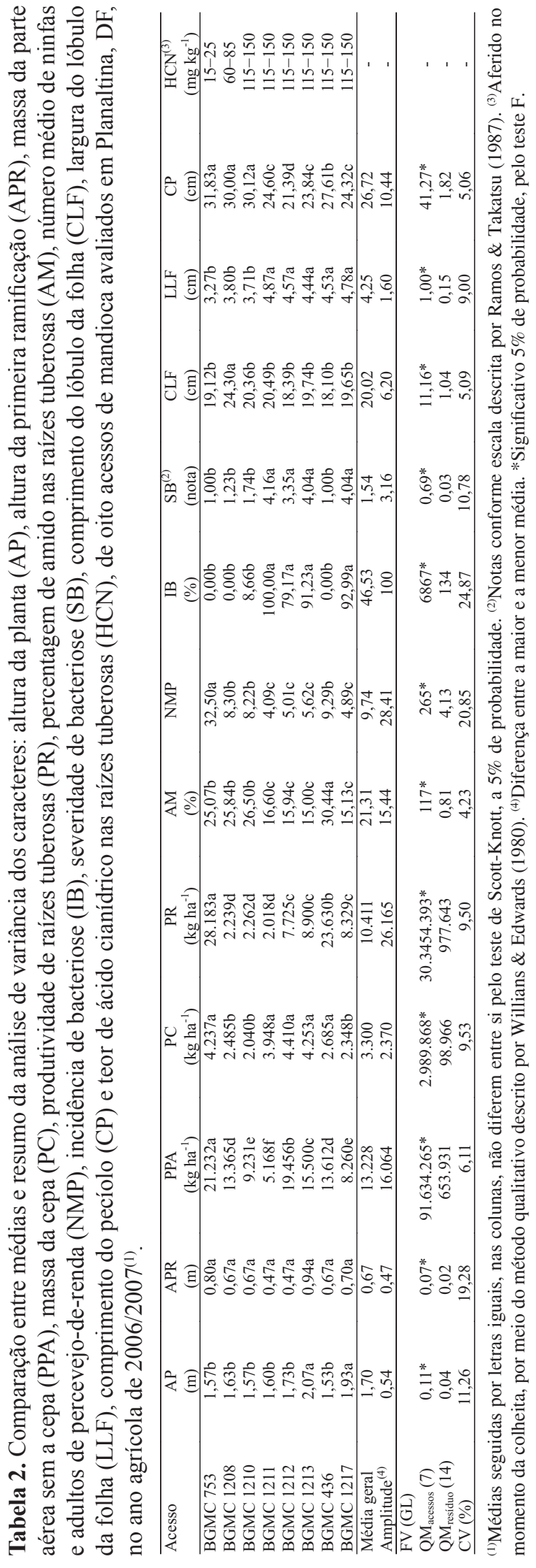


nos acessos açucarados, foi a baixa incidência de ninfas e adultos de percevejo-de-renda (NMP), o que aponta para a existência de algum mecanismo de resistência desses acessos à praga (Tabela 2).

Entre os acessos avaliados, apenas as variedades recomendadas para o cultivo na região do Cerrado brasileiro - para mesa (BGMC 753) e para indústria (BGMC 436) - revelaram teores de ácido cianídrico ( $\mathrm{HCN})$ nas raízes tuberosas abaixo de $100 \mathrm{mg} \mathrm{kg}^{-1} \mathrm{e}$, portanto, podem ter suas raízes consumidas in natura (na alimentação humana ou animal) ou processadas (Tabela 2). Os demais acessos avaliados necessitam que, antes do consumo, suas raízes tuberosas sejam processadas, para que o excesso de $\mathrm{HCN}$ seja eliminado.

Também é interessante observar que as mandiocas açucaradas não reproduziram teores de amido inferiores a $6 \%$, nas raízes tuberosas (Tabela 2), conforme havia sido relatado por Carvalho et al. (2004). Essa variação na estimativa dos teores de amido, nas raízes tuberosas, pode estar relacionada aos diferentes métodos de quantificação empregados: kit de análise do teor de amido (Carvalho et al., 2004) e método da banca hidrostática (utilizado no presente trabalho), bem como ao ambiente da região do Cerrado brasileiro, caracterizado pela ocorrência de estações chuvosas e de seca bem definidas, o que não corresponde ao clima da região Amazônica do Estado do Pará, onde as mandiocas açucaradas foram coletadas.

Adistânciagenética, estimada por meio dos caracteres quantitativos, evidenciou que os acessos geneticamente mais próximos foram BGMC 1208 e BGMC 1210, ambas variedades não açucaradas locais, coletadas no Estado do Pará, em municípios diferentes (Tabela 1); a maior distância genética foi observada entre os acessos BGMC 1211, açucarado, e BGMC 753, variedade melhorada de mandioca de mesa, recomendada para o plantio na região do Cerrado brasileiro. Na Figura 1 A, pode-se verificar que os valores percentuais de coincidência nos agrupamentos após 500 ciclos de "bootstrapping" mostraram que o acesso BGMC 753 apresentou elevada divergência em relação aos demais acessos avaliados, o que ocorreu, principalmente, em razão de esse acesso ter apresentado elevados valores de PPA, PR e NMP (Tabela 2 e Figura 1 A); pode-se verificar, ainda, que o acesso BGMC 436, variedade para indústria recomendada para o cultivo na região do Cerrado brasileiro, mostrou elevada divergência
A

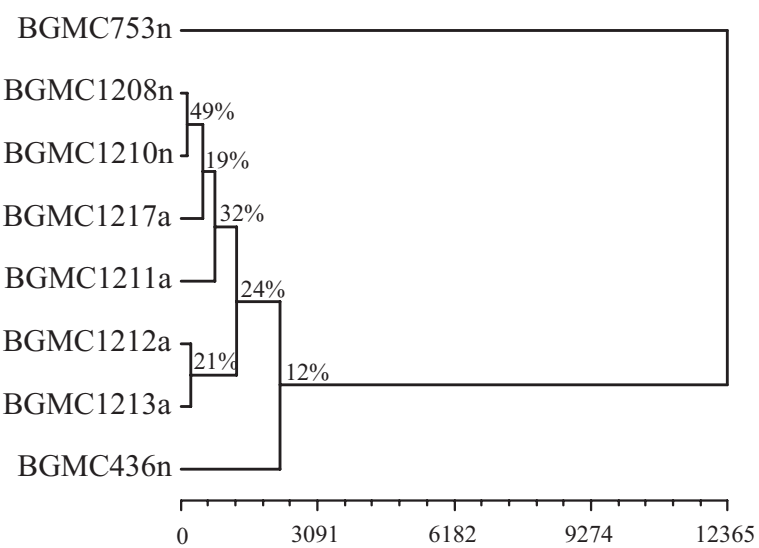

B

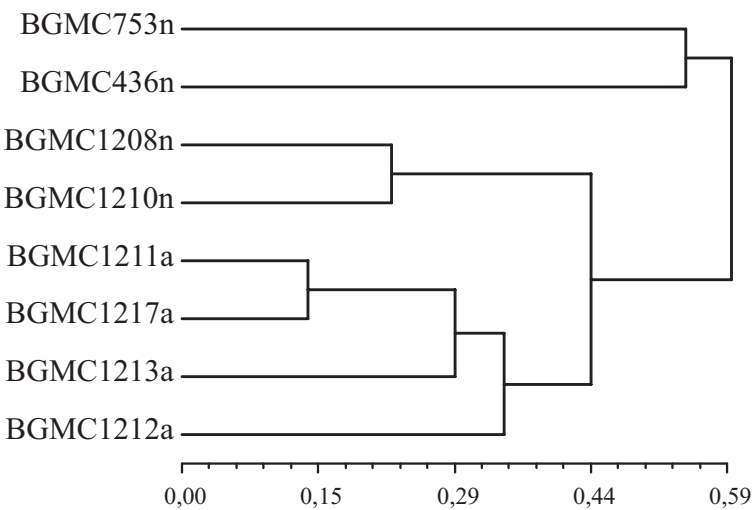

C

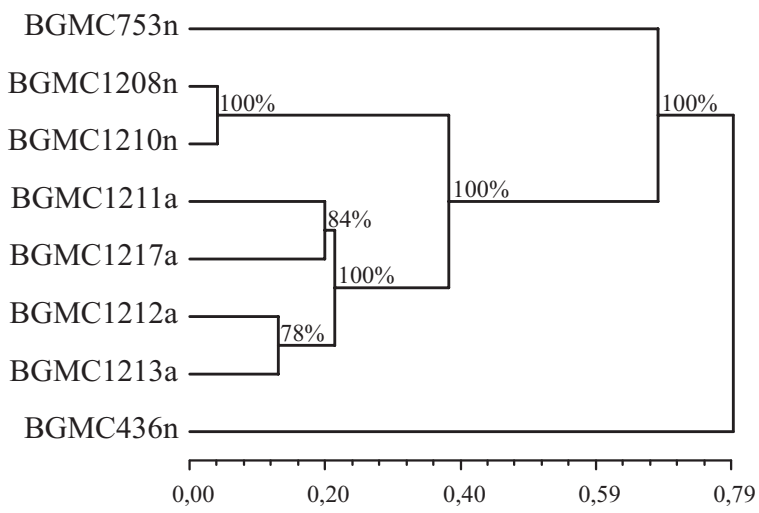

Figura 1. Dendrogramas resultantes da análise de agrupamento de quatro acessos de mandioca açucarados (a) e quatro não açucarados (n), obtidos pelo método UPGMA, por meio: A) da distância de Mahalanobis (com base em 12 caracteres quantitativos), com coeficiente de correlação cofenética $\mathrm{r}=0,93$; B) do complemento do índice de coincidência simples (com base em 22 marcadores morfológicos), com coeficiente de correlação cofenética $\mathrm{r}=0,88$; e C) do complemento do índice de similaridade de Jacard, obtido a partir da análise de 96 marcadores RAPD, com coeficiente de correlação cofenética $r=0,99$. Os valores encontrados nos grupos indicam o valor percentual de vezes em que os genótipos foram agrupados em 500 ciclos de análise de "bootstrapping". 
genética em relação aos demais acessos locais avaliados (variedades açucaradas ou não), porém em menor magnitude que o acesso BGMC 753 (Figura $1 \mathrm{~A}$ ). $\mathrm{O}$ coeficiente de correlação cofenética do dendrograma $(r=0,93)$ mostrou elevado ajuste entre a representação gráfica das distâncias genéticas e a matriz de distância generalizada de Mahalanobis, o que assegura as inferências realizadas com base na avaliação visual da Figura 1 A.

Entre os 33 marcadores de caracteres qualitativos avaliados, $22(67 \%)$ apresentaram variabilidade entre os acessos de mandioca analisados (Tabela 3), o que revela a existência de ampla divergência entre os acessos estudados, quanto aos marcadores morfológicos aferidos, e a eficiência desses na estimativa da divergência genética em mandioca, como já havia sido reportado por Sambatti et al. (2000) e Mkumbira et al. (2003). Todavia, 11 caracteres qualitativos $(33 \%)$ não revelaram nenhuma variabilidade, pois todos os acessos apresentaram floração, ausência de pubescência no broto apical, estípulas longas e lancinadas, hábito de crescimento do caule reto, folhas verde-escuras, pecíolo na posição horizontal, córtex do caule verdeescuro, córtex da raiz branco ou creme, raízes com textura da epiderme rugosa e de difícil destaque.

A dissimilaridade genética, estimada por meio dos caracteres qualitativos que apresentaram variação no grupo de acessos, evidenciou que os acessos mais similares foram BGMC 1211 e BGMC 1217, ambos açucarados, coletados no mesmo município no Estado do Pará (Tabela 1). A maior dissimilaridade genética foi verificada entre os acessos BGMC 1211, açucarado, e BGMC 753, variedade melhorada de mandioca de mesa, recomendada para o plantio na região do Cerrado brasileiro. Na Figura 1 B, observa-se a formação de três grupos: o primeiro formado pelos dois acessos locais não açucarados BGMC 1208 e BGMC 1210; o segundo formado pelos acessos açucarados; e o terceiro formado pelos dois acessos recomendados para o cultivo na região do Cerrado, BGMC 436 e BGMC 753. O coeficiente de correlação cofenética do dendrograma $(r=0,88)$ mostrou elevado ajuste entre a representação gráfica da dissimilaridade e a matriz de dissimilaridade genética original, o que confere confiabilidade às inferências realizadas por meio da avaliação visual da Figura $1 \mathrm{~B}$.

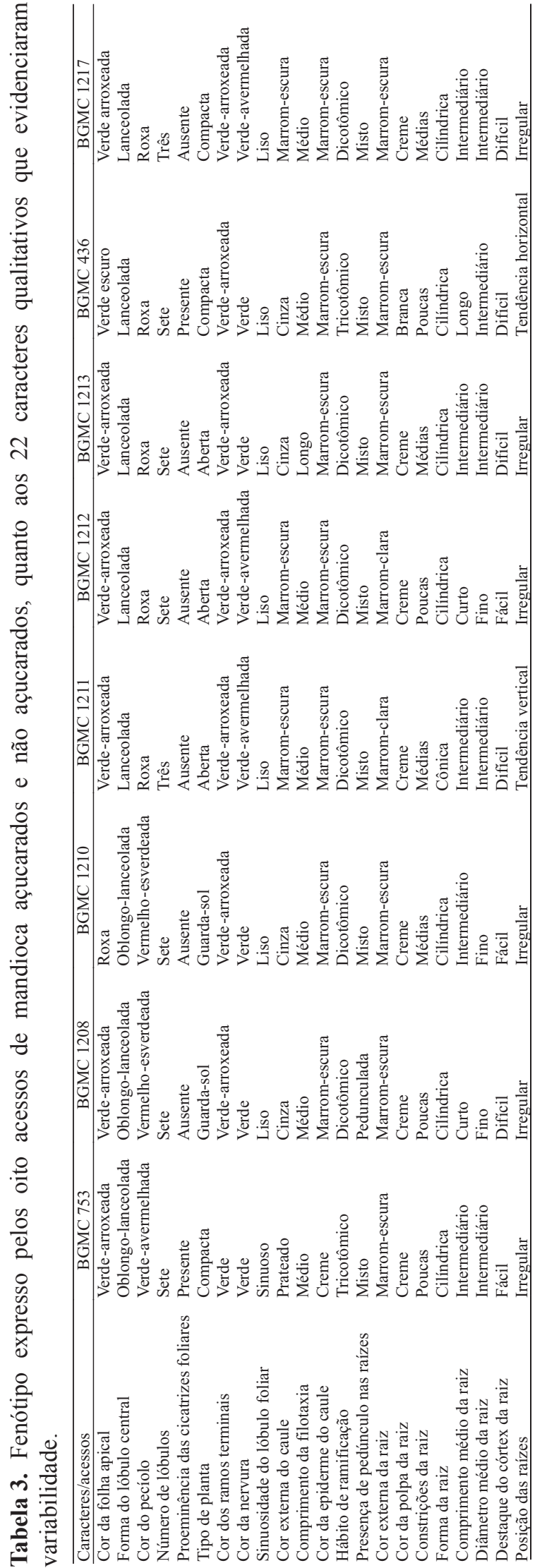


Os 12 iniciadores RAPD utilizados geraram o total de 131 marcadores, dos quais 96 (73\%) foram polimórficos (Tabela 4), o que evidencia a existência de variabilidade genética e eficiência da técnica de RAPD, na detecção da divergência genética, nos oito acessos de mandioca estudados. A eficiência dos marcadores RAPD, na detecção de variabilidade genética entre acessos de mandioca, já havia sido relatada por Colombo et al. (2000), Carvalho \& Schaal (2001), Asante \& Offei (2003) e Zacarias et al. (2004).

Entre os iniciadores utilizados, o maior número de bandas polimórficas foi evidenciado pelo OPG-08, com 12 bandas, e o menor número foi $\mathrm{OPH}-10 \mathrm{com}$ três (Tabela 4). Em meio às bandas polimórficas, foram detectadas bandas geradas pelos iniciadores OPH-10 e OPH-17, com pesos moleculares de 600 e $1.000 \mathrm{pb}$, respectivamente, que diferenciam acessos não açucarados dos açucarados. Essas bandas podem constituir marcadores com potencial para o mapeamento genético deste fenótipo, no genoma da mandioca, para a determinação dos genes envolvidos na expressão do caráter fenótipo açucarado, nas raízes tuberosas de mandioca, e sua utilização na seleção assistida por marcadores moleculares (Okogbenin et al., 2006).

A dissimilaridade genética, estimada por meio dos 96 marcadores RAPD que apresentaram variação nos acessos de mandioca avaliados, evidenciou que os acessos mais similares foram BGMC 1208 e BGMC 1210 - ambos não açucarados, introduzidos no BGMC como açucarados e coletados em municípios distintos do Estado do Pará (Tabela 1) - e que os menos similares foram o BGMC 1212, açucarado, e BGMC 436, variedade melhorada de mandioca de indústria, recomendada para o plantio na região

Tabela 4. Iniciadores utilizados para a obtenção dos marcadores RAPD e o respectivo número de bandas polimórficas e monomórficas.

\begin{tabular}{llcc}
\hline Iniciadores & $\begin{array}{c}\text { Seqüência } \\
5^{\prime} \rightarrow 3^{\prime}\end{array}$ & $\begin{array}{c}\text { Número de bandas } \\
\text { polimórficas }\end{array}$ & $\begin{array}{c}\text { Número de bandas } \\
\text { monomórficas }\end{array}$ \\
\hline OPD-02 & GGACCCAACC & 5 & 0 \\
OPD-08 & GTGTGCCCCA & 9 & 4 \\
OPD-18 & GAGAGCCAAC & 9 & 9 \\
OPF-08 & GGGATATCGG & 11 & 2 \\
OPG-05 & CTGAGACGGA & 10 & 4 \\
OPG-08 & TCACGTCCAC & 12 & 0 \\
OPG-09 & CTGACGTCAC & 9 & 1 \\
OPG-15 & ACTGGGACTC & 5 & 2 \\
OPG-16 & AGCGTCCTCC & 5 & 4 \\
OPH-10 & CCTACGTCAG & 3 & 3 \\
OPH-16 & TCTCAGCTGG & 10 & 3 \\
OPH-17 & CACTCTCCTC & 8 & 3 \\
Total & & 96 & 35 \\
\hline
\end{tabular}

do Cerrado brasileiro. Os valores percentuais de agrupamentos coincidentes, após 500 ciclos de "bootstrapping", alocaram os acessos em quatro grupos: o primeiro grupo - BGMC 1208 e BGMC 1210 - é local, com percentagem de agrupamentos coincidentes de $100 \%$; o segundo grupo foi, formado pelos acessos açucarados BGMC 1211, BGMC 1217, BGMC 1212 e BGMC 1213, com percentagem de agrupamentos coincidentes de $100 \%$; o terceiro grupo foi formado pelo acesso BGMC 753; e o quarto grupo foi formado pelo acesso BGMC 436. O coeficiente de correlação cofenética do dendrograma $(r=0,99)$ evidenciou elevado ajuste entre a representação gráfica da dissimilaridade genética e a matriz original, o que assegura as inferências realizadas por meio da avaliação visual da Figura $1 \mathrm{C}$.

Os resultados obtidos revelaram a existência de moderada variabilidade entre os acessos açucarados quanto aos caracteres quantitativos, caracteres qualitativos e marcadores RAPD (Figuras 1 A, B e C). A inexistência de similaridade de $100 \%$, entre os acessos açucarados, para as metodologias de quantificação da divergência genética utilizadas, tem reflexos diretos no melhoramento genético que é dependente de variabilidade (Allard, 1999), em especial para a cultura da mandioca, que é alógama e sofre depressão endogâmica (Cebalos et al., 2004). Do ponto de vista da conservação de germoplasma, esse resultado revela a inexistência de duplicatas no BGMC, entre aos acessos açucarados, e a necessidade da conservação desse acessos.

As técnicas utilizadas também foram eficientes na discriminação dos acessos, em função do fenótipo açúcar nas raízes, pois nenhum acesso não açucarado agrupou-se com acessos açucarados, no primeiro nível hierárquico (Figuras 1 A, B e C). Os acessos BGMC 1208 e BGMC 1210, que haviam sido introduzidos no BGMC como açucarados, foram detectados como não açucarados, somente após a coleta de amostras foliares, para a execução deste estudo; observou-se que nas condições do Cerrado brasileiro, esses acessos não apresentaram fenótipo açucarado. Em razão de possível falha ocorrida na etiquetagem desses acessos durante a coleta, eles formaram um grupo isolado em todas as técnicas empregadas, o que permite o estabelecimento da hipótese de que esses acessos apresentam um "backgroud" genético diferente dos acessos açucarados e das variedades recomendadas para o cultivo na região 
do Cerrado brasileiro. Entretanto, essa hipótese deve ser averiguada em estudos com a inclusão de um maior número de acessos açucarados e não açucarados (locais e melhorados) de diferentes origens. A necessidade da realização de tais experimentos se baseia nos resultados reportados por Colombo et al. (2000), que avaliaram, por meio de marcadores RAPD, 126 acessos de mandioca de quatro origens diferentes e detectaram uma tendência de agrupamento, em razão das condições ecológicas do local de origem dos acessos.

Foi encontrada elevada divergência genética entre os acessos BGMC 753 e BGMC 436 - oriundos de programas de melhoramento genético - e os demais acessos açucarados ou não açucarados (Figuras 1 A, B e C), decorrente do processo de seleção artificial.

Entre as técnicas de acesso à divergência genética empregadas, as de maior correlação foram as de dissimilaridade genética, por meio de marcadores RAPD e por meio de caracteres qualitativos $(r=0,83)$, altamente significativas pelo teste de comparação de matrizes de Mantel, com 1.000 permutações. Essas duas técnicas detectaram, em comum, a presença de dois agrupamentos fortes, um formado pelos acessos locais não açucarados (BGMC 1208 e BGMC 1210), e outro pelos acessos açucarados (BGMC 1211, BGMC 1212, BGMC 1213 e BGMC 1217). A diferença entre as técnicas foi que na análise com marcadores RAPD, o acesso BGMC 753 revelou maior similaridade genética com os demais acessos do que na matriz de dissimilaridade obtida por meio dos caracteres qualitativos (Figura $1 \mathrm{~B}$ e C). No entanto, a matriz de distâncias genéticas estimadas por meio de caracteres quantitativos mostrou associação significativa $(p<0,05)$, porém moderada, com as matrizes de dissimilaridade obtidas a partir de marcadores RAPD $(\mathrm{r}=0,50)$ e caracteres qualitativos $(\mathrm{r}=0,58)$.

A elevada associação entre a divergência estimada por marcadores moleculares e caracteres qualitativos e a baixa associação entre ambos e os caracteres quantitativos podem ser explicadas pelo fato de grande parte da variação detectada pelos marcadores moleculares e caracteres qualitativos aferidos ser do tipo não adaptativa e, portanto, não sujeita à seleção (natural e artificial), ao contrário dos caracteres indicadores quantitativos aferidos que são sujeitos tanto à seleção natural quanto à artificial (Vieira et al., 2007a). A utilização de maior número de dados moleculares e caracteres qualitativos e a menor influência do ambiente sobre esses, em relação aos caracteres quantitativos, também podem explicar as correlações obtidas. Assim, fica evidente que as estimativas das distâncias/dissimilaridades genéticas serão tão mais próximas, quanto maior for a associação entre os locos que controlam os caracteres quantitativos (QTL) e os locos que controlam os marcadores moleculares e caracteres qualitativos avaliados (Máric et al., 2004; Roy et al., 2004).

\section{Conclusões}

1. Há divergência genética entre acessos de mandioca açucarados e não açucarados.

2. Há elevada associação entre as distâncias genéticas estimadas por meio de marcadores moleculares e caracteres qualitativos, e moderada associação com a divergência estimada por meio de caracteres quantitativos.

\section{Agradecimentos}

À Empresa Brasileira de Pesquisa Agropecuária, à Fundação Banco do Brasil, ao Conselho Nacional de Desenvolvimento Científico e Tecnológico e ao Programa Biodiversidade Brasil-Itália, pelo apoio financeiro.

\section{Referências}

ALLARD, R.W. Principles of plant breeding. $2^{\text {nd }}$ ed. New York: John Wiley, 1999. 254p

ASANTE, I.K.; OFFEI, S.K. RAPD-based genetic diversity study of fifty cassava (Manihot esculenta Crantz) genotypes. Euphytica, v.131, p.113-119, 2003.

BORGES, M.F.; FUKUDA, W.M.G.; ROSSETTI, A.G. Avaliação de variedades de mandioca para consumo humano. Pesquisa Agropecuária Brasileira, v.37, p.1559-1565, 2002.

CARVAlHO, L.J.C.B.; CABRAL, G.B.; CAMPOS, L. Raiz de reserva de mandioca: um sistema biológico de múltipla utilidade. Brasília: Embrapa Recursos Genéticos e Biotecnologia, 2000. 16p. (Embrapa Recursos Genéticos e Biotecnologia. Documentos, 44).

CARVALHO, L.J.C.B.; SCHAAL, B.A. Assessing genetic diversity in the cassava (Manihot esculenta Crantz) germplasm collection in Brazil using PCR-based markers. Euphytica, v.120, p.133-142, 2001.

CARVALHO, L.J.C.B.; SOUZA, C.R.B.; CASCARDO, J.C.M.; BLOCH JUNIOR, C.; CAMPOS, L. Identification and characterization of novel cassava (Manihot esculenta Crantz) clone with high free-sugar content and novel starch. Plant Molecular Biology, v.56, p.643-659, 2004. 
CEBALlOS, H.; IGLESIAS, C.A.; PÉREZ, J.C.; DIXON, A.G.O. Cassava breeding: opportunities and challenges. Plant Molecular Biology, v.56, p.503-516, 2004.

COLOMBO, C.; SECOND, G.; CHARRIER, A. Diversity within American cassava germplasm based on RAPD markers. Genetics and Molecular Biology, v.31, p.189-199, 2000.

COSTA, A.M.; FALEIRO, F.G.; KARIA, C.T.; SHIRATSUCHI, L.S.; ANDRADE, R.P.; LOPES, G.K.B. Variabilidade genética e ecológica de Stylosanthes macrocephala determinadas por RAPD e SIG. Pesquisa Agropecuária Brasileira, v.40, p.899-909, 2005.

CRUZ, C.D. Programa genes: aplicativo computacional em genética e estatística. Viçosa: UFV, 2001. 648p.

FALEIRO, F.G.; FALEIRO, A.S.G.; CORDEIRO, M.C.R.; KARIA, C.T. Metodologia para operacionalizar a extração de DNA de espécies nativas do Cerrado. Planaltina: Embrapa Cerrados, 2003. 6p.

FERREIRA, C.F.; ALVES, E.; PESTANA, K.N.; JUNGHANS, D.T.; KOBAYASHI, A.K.; SANTOS, V.J.; SILVA, R.P.; SILVA, P.H.; SOARES, E.; KUKUDA, W. Molecular characterization of cassava (Manihot esculenta Crantz) with yellow-orange roots for beta-carotene improvement. Crop Breeding and Applied Genetics, v.8, p.23-29, 2008.

FUKUDA, W.M.G.; GUEVARA, C.L. Descritores morfológicos e agronômicos para a caracterização de mandioca (Manihot esculenta Crantz). Cruz das Almas: CNPMF, 1998. 38p.

GROSMANN, J.; FREITAS, A.G. Determinação do teor de matéria seca pelo método do peso específico em raízes de mandioca. Revista Agronômica, v.14, p.75-80, 1950.

JACCARD, P. Nouvelles recherches sur la distribution florale. Bulletin Société Vaudoise des Sciences Naturelles, v.44, p.223-270, 1908.

MAHALANOBIS, P.C. On the generalized distance in statistics. Proceedings of the National Institute of Sciences of India, New Delhi, v.2, p.4955, 1936.

MANTEL, N. The detection of disease clustering and a generalized regression approach. Cancer Research, v.27, p.209-220, 1967.

MÁRIC, S.; BOLARÍC, S.; MARTINCIC, J.; PEJÍC, I.; KOZUMPLINK, V. Genetic diversity of hexaploid wheat cultivars estimated by RAPD markers, morphological traits and coefficients of parentage. Plant Breeding, v.123, p.366-369, 2004.

MKUMBIRA, J.; CHIWONA-KARLTUN, L.; LAGERCRANTZ, U.; MAHUNGU, N.M.; SAKA, J.; MHONE, A.; BOKANGA, M.; BRIMER, L.; GULLBERG, U.; ROSLING, H. Classification of cassava into "bitter" and "cool" in Malawi: from farmer's perception to characterization by molecular markers. Euphytica, v.132, p.7-22, 2003.
NICK, C.; CARVALHO, M.; ASSIS, L.H.B.; CARVALHO, S.P. Genetic dissimilarity in cassava clones determined by multivariate techniques. Crop Breeding and Applied Genetics, v.8, p.104-110, 2008.

OKOGBENIN, E.; MARIN, J.; FREGENE, M. An SSR-based molecular genetic map of cassava. Euphytica, v.147, p.433-440, 2006.

OLSEN, K.M. SNPs, SSRs and inferences on cassava's origin. Plant Molecular Biology, v.56, p.517-526, 2004.

RAMOS, J.G.A.; TAKATSU, A. Avaliação da resistência de cultivares de mandioca à bacteriose em Goiás. Goiânia: Emgopa, 1987. 26p.

ROHLF, F.J. NTSYS-pc: numerical taxonomy and multivariate analysis system, version 2.1. New York: Exeter Software, 2000. 98p.

ROY, J.K.; LAKSHMIKUMARAN, M.S.; BALYAN, H.S.; GUPTA, P.K. AFLP-based genetic diversity and its comparison with diversity based on SSR, SAMPL, and phenotypic traits in bread wheat. Biochemical Genetics, v.42, p.43-59, 2004.

SAMBATTI, J.B.M.; MARTINS, P.S.; ANDO, A. Distribuição da diversidade isoenzimática e morfológica da mandioca na agricultura autóctone da 'Ubatuba'. Scientia Agricola, v.57, p.75-80, 2000.

SCOTT, A.J.; KNOTT, M.A. A cluster analysis methods for grouping means in the analysis of variance. Biometrics, v.30, p.507-512, 1974.

SOKAL, R.R.; ROHLF, F.J. The comparison of dendrograms by objective methods. Taxon, v.11, p.30-40, 1962.

SOUZA, L.S.; FIALHO, J.F. Cultivo da mandioca para a região do Cerrado. Cruz da Almas: Embrapa Mandioca e Fruticultura, 2003. 61p. (Sistema de produção, 8).

VIEIRA, E.A.; CARVALHO, F.I.F.; BERTAN, I.; KOPP, M.M.; ZIMMER, P.D.; BENIN, G.; SILVA, J.A.G.; HARTWIG, I.; MALONE, G.; OLIVEIRA, A.C. Association between genetic distances in wheat (Triticum aestivum) as estimated by AFLP and morphological markers. Genetics and Molecular Biology, v.30, p.392-399, 2007a.

VIEIRA, E.A.; FIALHO, J.F.F.; SILVA, M.S.; FALEIRO, F.G. Variabilidade genética do banco ativo de germoplasma de mandioca do Cerrado acessada por meio de descritores morfológicos. Planaltina: Embrapa Cerrados, 2007b. 15p.

WILLIAMS, H.J.; EDWARDS, T.G. Estimation of cyanide with alkaline picrate. Journal of the Science of Food and Agriculture, v.31, p.15-22, 1980.

ZACARIAS, A.M.; BOTHA, A.M.; LABUSCHAGNE, M.T.; BENESI, I.R.M. Characterization and genetic distance analysis of cassava (Manihot esculenta Crantz) germplasm from Mozambique using RAPD fingerprinting. Euphytica, v.138, p.49-53, 2004.

Recebido em 10 de setembro de 2008 e aprovado em 28 de novembro de 2008 